\title{
LA FORMACIÓN DEL CORAZÓN. SAL 33,15 Y SUS IMPLICACIONES PARA LA TEOLOGÍA DE LA EDUCACIÓN
}

\author{
Richard Edmundo Colmenares Chacón \\ Univ. Cat. Cecilio Acosta (Maracaibo - Venezuela) \\ richardcolmenares1981@gmail.com
}

Resumen: El artículo busca evidenciar el horizonte educativo que presenta el Salmo 33 y sus implicaciones doctrinales para la construcción criteriológica de la teología de la educación. Esto a partir del reconocimiento hímnico del salmo, en cuyo corpus encontramos una estructura a manera de péntada, formada por cinco enseñanzas que el salmista busca transmitir a sus destinatarios orantes. Consideramos central la cuarta enseñanza del salmo, razón por la cual la hemos desarrollado más en profundidad. Reconocemos en ella la formación del corazón, la cual es una acción formativa que Dios continúa realizando: Dios forma el corazón de cada uno discerniendo sus acciones.

Palabras clave: Tradición. Enseñanza. Educación. Discernimiento.

Abstract: The article seeks to demonstrate the educational horizon present in Psalm 33, and its doctrinal implications for the construction of a criteriological Theology of Education. This is based on the hymnal recognition of the psalm, in which corpus we find a structure in the form of a pentad, formed by five teachings that the Psalmist seeks to convey to his praying recipients. We consider the fourth teaching of the psalm to be central. For that reason, it has been the one we have developed in depth, recognizing in it the formation of the heart, which is a formative action that God continues to carry out: God forms the heart of each one by discerning his/her actions.

Keywords: Tradition. Teaching. Education. Discernment. 


\section{Introducción}

El reconocimiento de la función educativa de los Salmos es una aproximación exegética relativamente reciente ${ }^{1}$. Esta se inspira en la intuición de la "aproximación canónica" ${ }^{2}$, que reconoce una posible intencionalidad educativa en el ordenamiento final de los ciento cincuenta salmos en el Salterio hebreo ${ }^{3}$. El análisis de esta intencionalidad educativa de un salmo específico no se puede llevar a cabo sin tener en cuenta el orden canónico del Salterio y la posición que ocupa en él dicho salmo. Esta estructura tiene un propósito pedagógico para el editor final del libro, que ordena las cosas para que se puedan asimilar y aprender mejor, guiando paulatinamente la temática que el educador busca "transmitir" a sus destinatarios. El proceso de edición canónica del Salterio expresan que los ciento cincuenta salmos en su conjunto fueron vistos y asimilados como especiales e importantes para la vida del pueblo de Israel ${ }^{4}$.

Con el Salterio estamos delante de una intencionalidad educativa del editor final, que tiene como horizonte la formación de sus conciudadanos en temáticas muy concretas, de las cuales era necesario tomar conciencia para la supervivencia de la identidad del pueblo con el cual Dios había hecho alianza. Evidenciar la intencionalidad educativa presente en el Sal 33, dentro de la aproximación canónica, será un objetivo que este artículo busca reconocer, como orientación válida y certera para la teología de la educación.

\section{Una mirada a la teología de la educación}

La teología de la educación (TdE) es el estudio sistemático de los problemas educativos a la luz de la fe cristiana. En la TdE se subraya la interpretación cristiana del hecho educativo, donde la educación es el objeto material y la revelación el objeto formal ${ }^{5}$.

En primer lugar, la teología es una investigación hermenéutica de la Palabra de Dios; el teólogo siempre quiere entender e interpretar mejor esta

Cf. FIRTH, “Teaching”, 161.

2 Cf. Childs, Introduction, 504-525; Wilson, Editing, 18; Hossfeld - Zenger, I Psalm 1-50, 22; Barbiero, Dai Salmi, 13.

3 Cf. Brown, Psalms, preface ix.

${ }^{4}$ Cf. FIRTH, "Teaching", 162.

5 Cf. Groppo, “Teologia”, 254. 
Palabra utilizando todos los medios hermenéuticos que la cultura le proporcione. En 1946, en Bélgica, G. Thils se convirtió en el promotor de un estudio teológico sobre la "teología de las realidades terrenas", donde incluye también la educación. Aparece de esta manera la reflexión teológica sobre el hecho educativo, que más tarde se llamará "teología de la educación". Pero ¿cómo entiende esta argumentación teológica el hecho educativo? Para la TdE, este término responde al proceso de integración social y de transmisión cultural por el cual, en el contexto de situaciones históricas concretas, ambientales y familiares, se estructura la personalidad del educando.

Por su parte, la TdE como disciplina teológica reconoce que su objeto de estudio no es solo la educación, sino también la Palabra de Dios sobre la educación. Esta disciplina teológica encuentra su objeto de estudio en los procesos educativos que Dios quiso dar a conocer a los hombres y que están contenidos en la Escritura. La TdE es una hermenéutica de la Palabra de Dios sobre la educación. Por otra parte, reconociendo la presencia de precomprensiones en el teólogo, se requiere que el punto de partida de una TdE sean los problemas educativos presentes en la comunidad cristiana y, por ende, la confrontación de la fe con la cultura del medio ambiente en que se vive, con la finalidad de construir criteriologías adecuadas que proporcionen soluciones reales a la problemática educativa presente en la comunidad de creyentes. Esta problemática pedagógica de la comunidad cristiana empuja al teólogo a buscar nuevas interpretaciones en la Palabra de Dios sobre la educación. Es leer la Palabra de Dios en clave pedagógica.

Reconociendo el amplio panorama de esta disciplina teológica, el teólogo de la educación se pregunta: ¿qué dice la Palabra de Dios sobre la realidad educativa en su complejidad, en sí misma, en sus fundamentos antropológicos, en sus horizontes, en sus propósitos y en sus instituciones? Aparece de esta manera la TdE como un diálogo recíproco-asimétrico entre Palabra de Dios y hecho educativo. Y su investigación teológica, de tipo hermenéutico, tiene necesidad de una aproximación escriturística seria, científica y exegética que le permita al teólogo de la educación contemplar el misterio renovador que el texto sagrado nos ofrece con miras a reconocer las luces que puedan iluminar el hoy educativo de la familia humana. A esta aproximación escriturística que necesita la TdE responde el desarrollo de este artículo, que busca evidenciar el horizonte educativo presente en el Salmo 33. 


\section{El escenario canónico del Salmo 33}

Nuestra aproximación educativa tiene la necesidad de reconocer este escenario canónico en el cual está inserto el salmo, para así reconocer sus alcances pedagógicos en la intención del editor final del libro del Salterio. Abrazamos la idea canónica de reconocer cinco libros como estructuración básica del Salterio ${ }^{6}$. La división y estructura del primer libro (Sal 3-42) es muy discutida. Esta investigación asume aquí la división propuesta por G. Barbiero, en la cual sigue a otros grandes autores sobre los Salmos. Él reconoce que el primer libro está estructurado en cuatro colecciones de salmos, a saber:

- Primera colección: Sal 3-14.

- Segunda colección: Sal 15-24.

- Tercera colección: Sal 25-34.

- Cuarta colección: Sal 35-41.

Como podemos ver, nuestro Sal 33 pertenece a la tercera colección del primer libro del Salterio. Esta tercera colección (Sal 25-34) está estructurada a su vez de la siguiente manera:

- Sal 25-28: Súplica.

- Sal 29: Himno.

- Sal 30: Acción de gracias.

- Sal 31: Súplica.

- Sal 32: Acción de gracias.

- Sal 33: Himno.

- Sal 34: Acción de gracias.

Se puede evidenciar que aparecen dos series en esta tercera colección del primer libro. No es que la segunda sea una repetición de la primera, sino que se nota una argumentación que va siendo acumulativa. La segunda serie, que se inicia en el Sal 31, comienza a introducir el tema del "perdón", que será expuesto en el Sal 32. De esta concepción del perdón surge el Sal 33 , un himno de alegría como feliz reacción de alabanza gracias a la constatación del Sal 32 de que "el justo es el perdonado" (cf. Sal 32,5).

Por otro lado, el Sal 33 es el único salmo de la tercera colección (Sal 25-34) que no tiene título en el Texto Masorético (TM) ${ }^{7}$. Esta verificación

${ }^{6}$ La división en cinco libros es confirmada por las cuatro fórmulas doxológicas $(41,14 ; 72,18-19 ; 89,53 ; 106,48)$, cf. LoRENZIN, / Salmi, 17-18, y es patrimonio común de los estudios actuales de los Salmos, cf. E. Ruiz, "Rostros”, 77-78.

7 En el primer libro del Salterio (Sal 3-42) encontramos otro ejemplo de salmo sin título, este es Sal 10; lo que ha hecho pensar que Sal 9 y 10 constituyen un solo salmo acróstico. 
ha dado pie a muchas interpretaciones ${ }^{8}$. Pero nosotros, leyendo el TM, abrazamos la idea de un esquema de "constatación-reacción", donde a la "constatación" de aparecer el "justo" como el perdonado (Sal 32,5) le sigue la "reacción" del orante: un estallido de alegría expresado en el himno de alabanza que es el Sal 33.

Este primer verso del Sal 33 muestra puntos en común con el último versículo del Sal 32. Podemos verificar comparativamente que Sal 32,11 y Sal 33,1 hacen referencia al tetragrama sagrado, acompañado con una preposición $b^{e}$, así como también al grupo llamado șaddîqîm, "justos", y yešărîm, "rectos", y al verbo rnn, "gritar de júbilo". Estas similitudes nos hablan de la necesidad que hay de leer estos dos salmos (Sal 32 y 33) en "unidad pedagógica", a pesar de que sean claramente reconocidos dos salmos diferentes.

Queremos detenernos brevemente en el sustantivo șaddîqîm. Este término nos recuerda el Sal 1,5, que expone quién es el que merece la bienaventuranza: el bienaventurado es el justo. Este Sal 1, más que una introducción al Salterio, sería más bien un resumen del libro de los Salmos ${ }^{9}$; por consiguiente, este tema del "justo", en la edición final del libro, aparece como un leitmotiv del Salterio hebreo ${ }^{10}$. Podemos ver que estos "justos", junto con los $r^{r} \breve{s} \bar{a}$ 'îm o "impíos", que Sal 1,5 considera sus antónimos, son los dos personajes que conforman un juego de contraste retórico que implica, por un lado, que los "justos" son los seres humanos éticamente buenos ${ }^{11}$. Pero, además, en el Sal 32 notamos que la característica de "justo" delante de Dios es la de aquel que ha sentido el peso de su culpa $(32,4)$, que ha confesado su pecado $(32,5 \mathrm{~b})$, que ha sido perdonado $(32,5 \mathrm{c})$, que se dirige a Dios en la oración $(32,6)$ y que ve a Dios como su refugio $(32,7)$. Estos son los "justos", los perdonados, los que se regocijan en el Señor $(32,11)$.

A estos que se regocijan por sentirse perdonados por Dios es a quienes invita el salmista a exultar de alegría, también en el Señor, a través del imperativo rannenû: “Exulten de alegría!” (33,1a). A estos perdonados -que es ahora la forma de entender el salmista a los "justos"- es a los que

${ }^{8}$ Cf. BARBIERo, /l regno, 25; sobre todo en el hecho de verificar que, en los LXX, el salmo sí posee una referencia a David en el título, que busca direccionar al lector griego a considerar este Salmo 33 (32) como un salmo davídico.

9 Cf. Dahood, Psalms 1, 1.

10 Esta conciencia sobre el "justo" la podemos encontrar también en Sal 1,5.6; 32,$11 ; 33,1 ; 34,16 ; 37,17.29 .39 ; 52,8 ; 69,29 ; 97,12 ; 118,15.20 ; 140,14 ; 142,8 ; 146,8$.

11 La congregación de los justos (cf. Sal 1,5) es una adaptación ética de una frase mitológica cuyo original describe el consejo de los buenos en la religión cananea (UT, 128: III:7, 'dt ilm), cf. Dahood, Psalms 1, 5. 
invita el orante a alabar al Señor. Ellos son ahora los rectos, de los cuales es propia la alabanza $(33,1 b)$.

Como podemos ver, este escenario canónico del Sal 33 revela la importancia pedagógica de este salmo, ya que es toda una invitación a la alegría que poco a poco está comunicando una enseñanza central para la vida del orante que se acerca al Salterio recurriendo a esta forma poética hímnica que se inicia con la invitación a la alabanza ${ }^{12}$.

Estos dos salmos (32 y 33) han sido dispuestos en el Salterio en estilo didáctico: confesión e instrucción (Sal 32), oración e instrucción (Sal $33)^{13}$. ¿Quiénes son los justos? Los "perdonados" ${ }^{14}$. Es un nuevo contenido de fe, una nueva forma de entender a los "justos", que el editor final del Salterio quiere "transmitir" a los destinatarios de su momento histórico. Y ha querido enfatizar este nuevo contenido de fe disponiendo en unidad pedagógica estos dos salmos. La alegría del himno (Sal 33) es la reacción natural a la constatación de misericordia que caracteriza ahora a los justos: ellos son los perdonados (Sal 32,5).

\section{Un rastro de la intencionalidad educativa presente en el Salmo 33}

Este hecho de "transmitir" un contenido nuevo ya desvela una intencionalidad educativa. No podemos perder de vista que la educación comporta una gran carga de "transmisión", no solo de ideas, sino también de sentimientos, de aspiraciones, de perspectivas que brindan al conocimiento impartido veracidad o falsedad.

Cuando se educa, se hace porque se cree necesario "transmitir" una visión de la realidad a aquellos que viven en ella, ofreciendo un oportuno horizonte de valores, un conjunto de conocimientos y principios que se consideran no solo válidos, sino también necesarios para reconocer la bondad y la verdad de la vida ${ }^{15}$. Como se puede ver, para "transmitir" un contenido nuevo se hace necesaria una estrategia pedagógica que pasa a través de la forma en la cual está presentado el contenido conceptual. La forma

12 Cf. GUNKEL, Introducción, 48-49.

13 Cf. Schaefer, Psalms, 81.

14 Nos dice el Prof. Eleuterio Ruiz, en cuanto a la misericordia, que, más allá de su aspecto de compasión para con el que sufre, se encuentra también en relación con el perdón del pecado, sobre todo en Sal 32,5, cf. E. Ruiz, "Rostros", 85.

15 Cf. Sabetta, “Educare", 6. 
lingüística que el salmista ha escogido para "transmitir" este contenido conceptual que recoge el Sal 33 es el género literario hímnico.

Hermann Gunkel, y con él la mayoría de los exegetas posteriores ${ }^{16}$, ha reconocido el Sal 33 como un himno, indicando que este es uno de los géneros literarios más fáciles de reconocer ${ }^{17}$. Por lo general, los himnos comienzan con una introducción explícita que invita al júbilo y al canto utilizando el imperativo plural ${ }^{18}$; así lo vemos en los tres imperativos que inician los tres primeros versículos de nuestro Sal 33. A esta introducción le sigue un cuerpo, que Gunkel llama "parte central", y finaliza el salmo una conclusión, la cual puede retomar o contraponer temas ya expresados en la introducción.

Se puede ver que el Sal 33 obedece a este esquema hímnico. Sin embargo, se verifica en él una gran cantidad de citas implícitas de diversos pasajes de la Escritura ${ }^{19}$, lo que justifica la calificación de este salmo como un salmo antológico ${ }^{20}$. Es decir, el salmista recogió textos de la Escritura para construir el mensaje que este himno de alabanza quiere "transmitir" a sus lectores. Apoya esta idea el hecho de reconocer la composición tardía de este Sal 33, el cual debe pertenecer al período helenístico y, posiblemente, al período macabeo; esto en razón de las referencias al rey, al guerrero, a los caballos y a la guerra que vemos en los vv. 16.17; y también al júbilo de adoración hecha con instrumentos que vemos en los vv. 2.3 ${ }^{21}$. Pero una verificación que salta a la vista es que este Sal 33 tiene 22 versos, el mismo número de letras que posee el alfabeto hebreo, por lo que también ha sido calificado como un salmo alfabético ${ }^{22}$ que desvela una intencionalidad didáctica en el hecho de invitar al orante a querer brindar a Dios una alaban-

16 Cf. Dahood, Psalms 1, 33; Alonso Schökel - Carniti, Salmos, I, 495; Ravasi, Salmi I, 595; Ammassari, Il Salterio, I, 256; Gerstenberger, Psalms, 144; Kraus, Los Salmos, I, 532; ; Mays, Psalms, 148; Limburg, Psalms, 107; Schaefer, Psalms, 81; Lorenzin, Salmi, 151; Alter, Psalms, 113; Vangemeren, “Psalms", 317; Aparicio, Comentario filológico, 198; JACOBSON, "Psalm 33: The hesed", 310.

17 Cf. GUNKEL, Introducción, 47.

18 Cf. ib., 48.

19 V. $3 a$ de Is 42,10 / v. 3 b de Is 23,16/v. 7 de Job 38,22 / v. 9a de Gn 1,3/v. 11 de Is 40,$8 ; 46,10 ; 51,6.8 ; 55,8$ / v. 13 de Sal 11,4; 14,2 / v. 15 de Za 12,1/v. 16 de Dt 33,29 / v. 17 de $\operatorname{Pr} 21,31$ / v. 22 de Sal 90,17.

20 Cf. Gerstenberger, Psalms, 144. Barbiero se apoya en esta constatación para expresar que este Salmo 33 no obedece a un género literario puro, pero, como ya hemos citado, toda la crítica reconoce este salmo como un himno, cf. cita n. 16.

21 Cf. Briggs, Psalms, 286.

22 Cf. Mars, Psalms, 148. 
za total, desde la A hasta la $\mathrm{Z}^{23}$. Otros autores prefieren interpretar este fenómeno como una invitación a orar al Señor continuamente ${ }^{24}$. Sea cual fuere la interpretación que escojamos, se hace evidente que esta invitación a alabar a Dios, constante o total, debe ser enseñada. Con lo cual, esta característica alfabética del Sal 33 continúa revelando un rastro de la intencionalidad educativa que motivó al salmista a construir este salmo, el cual invita a los perdonados del Sal 32 a cantarle al Señor un cántico nuevo con el Sal 33.

\section{El Texto y la problemática textual del Salmo 33}

Luego de haber expuesto las coordinantes interpretativas en las cuales se desea mover esta investigación, dispongámonos a introducirnos en el universo exegético del Sal 33, con miras a seguir evidenciando su intencionalidad pedagógica y sus contenidos educativos como premisas válidas para el educador cristiano. Empezaremos por proponer una traducción propia del texto hebreo, fruto del análisis morfo-sintáctico y semántico que hemos hecho del TM. También haremos citaciones con letras sobre las palabras de la traducción que consideramos relevantes; estas citaciones pondrán en evidencia algunos problemas textuales y también la fuerza semántica de ciertos términos presentes en el salmo.

${ }^{1}$ Exulten de alegría a los justos en el Señor, de los rectos es propia la alabanza,

${ }^{2}$ den gracias al Señor con la lira ${ }^{\mathrm{b}}$, con el arpa de diez cuerdas entónenle a él,

${ }^{3}$ canten a él ${ }^{\mathrm{c}}$ un cántico nuevo, interpreten bien durante la aclamación,

${ }^{4}$ porque recta es la palabra del Señor, y todas sus acciones son leales ${ }^{\mathrm{d}}$.

${ }^{a}$ Esta expresión («exulten de alegría) busca interpretar el primer verbo imperativo piel del TM con el cual se introduce el salmo: rannenû, de la raíz rnn, que significa "júbilo" o "alegría". Como se indicó, el verbo aparece también en el último versículo del Sal 32, lo que plantea otro indicio para considerar la intención editorial de leer en "unidad pedagógica" estos dos salmos.

${ }_{23}$ Cf. Lorenzin, I Salmi, 151.
24 Cf. Limburg, Psalms, 107. 
${ }^{b}$ Con el Sal 33 encontramos por primera vez en el Salterio la mención de instrumentos musicales: la "lira", kinnôr, que según Flavio Josefo tiene doce cuerdas. Era conocida con el mismo nombre en ugarítico, también como un instrumento de doce cuerdas ${ }^{25}$. De modo que la referencia a una "lira" compuesta por doce cuerdas puede estar aquí fuera de duda.

${ }^{c}$ BHS indica que unos pocos manuscritos del targum sustituyen esta partícula preposicional lo por la expresión lyhwh, seguramente buscando aclarar que el canto debe estar dirigido a Dios. Pero realmente no hay necesidad de asumir esto, ya que la partícula lô está finalizando el versículo anterior y reaparece al final del v. 12, igualmente haciendo referencia a YHWH. Agregar esta expresión del targum cambiaría la fuerza numérica que el nombre de YHWH tiene en el salmo: el tetragrama aparece doce veces en toda la extensión del Sal 33, expresando pedagógicamente la intención del salmista de enseñar que toda la alabanza del pueblo de la alianza, conformado por doce tribus, es solo para YHWH, el Dios verdadero creador de todo.

${ }^{d}$ El sustantivo'ěmûnāh viene de la raíz 'mn y significa "ser fiel", "confiable". De esta raíz, usada en el NT de manera exclamativa (cf. Jn $5,24)$, viene la palabra "amén", con la cual finalizamos nuestras oraciones en la liturgia. La presencia de este término es importante para establecer la antítesis temática que el salmo plantea: fidelidad de Dios (v. 4) versus infidelidad de los hombres (vv. 16-17).

${ }^{5}$ Amando ${ }^{\text {e }}$ la justicia y el derecho, la misericordia del Señor llena la tierra,

${ }^{6}$ por la palabra del Señor fueron hechos los cielos, por el aliento de su boca, todos los ejércitos,

${ }^{7}$ reuniendo ${ }^{\mathrm{f}}$ en dique las aguas del mar, dando ${ }^{\mathrm{g}}$ depósito a los abismos.

${ }^{e}$ El participio 'ōhēb, del verbo 'āhab, "amar", lo entendemos en referencia a $\mathrm{YHWH}^{26}$. También vemos que la retórica del salmo prefiere una comprensión nominal de la serie de participios que 'ōhēb inaugura ${ }^{27}$ y que nos permiten ver acciones realizadas por YHWH; es decir, es YHWH el que ama la justicia y el derecho, y esta es la misericordia que llena la tierra.

${ }^{f}$ El segundo participio de la serie inaugurada hace referencia a YHWH, que reúne en un dique las aguas marinas.

25 Cf. Ravasi, Salmi I, 596.

26 Cf. Lohfink, "Bundesformel”, 89.

27 Cf. JacoBson, “The hesed", 311, cf. nota 7. 
${ }^{g}$ El participio nōtēn, del verbo nātan, "dar", traducido literalmente, por la fuerza semántica que significa el hecho del "dar" por parte de Dios a los hombres.

${ }^{8}$ Que tema ${ }^{\mathrm{h}}$ al Señor toda la tierra, delante de él tiemblen ${ }^{\mathrm{i}}$ todos los habitantes del mundo,

${ }^{9}$ porque él lo dijo y existió, él lo mandó y se puso en pie.

${ }^{h}$ El yusivo yîr' $\hat{u}$, de yārē', "temer", expresa el fundamento de la conciencia sapiencial judía sobre el temor de Dios (Pr 1,7) y va entendido de manera antónima al "miedo". Temer a Dios es respetar su palabra y saber que él es el creador del mundo, que solo él hace posible lo que parece imposible (Lc 1,37). El TM, en el v. 8a, deja ver un problema de concordancia de números, ya que el verbo está en plural, yîr'û: "que le teman", y el complemento está en singular, kol-hā'āreș, "toda la tierra". Leyendo el verbo como volitivo, hemos optado por leer el verbo al singular, de aquí nuestra traducción: "Que tema al Señor toda la tierra".

${ }^{i}$ El verbo gûr, "temblar de pavor", es el segundo yusivo del verso; marca la diferencia entre "temor" como respeto y "temblor" entendido como miedo. Es la opción del "temor de Dios" la que el salmista ha tomado y desarrollado en el salmo, la cual quiere inspirar pedagógicamente en sus destinatarios orantes. No por casualidad se vuelve a hacer referencia a los temerosos de Dios en el v. 18.

${ }^{10}$ El Señor anula el plan de las naciones,

frustra los proyectos de los pueblos.

${ }^{11}$ El plan del Señor por siempre está en pie,

los proyectos de su corazón de edad en edad.

${ }^{12}$ Bienaventurada la nación que tiene a YHWH como su Dios, el pueblo escogido como posesión suya.

${ }^{13}$ desde el cielo mira el Señor, ve a todos los hijos de Adán,

${ }^{14}$ desde su trono sentado el Señor observa a todos los habitantes de la tierra,

${ }^{15}$ formando ${ }^{\mathrm{j}}$ el corazón de cada uno ${ }^{\mathrm{k}}$, discerniendo ${ }^{1}$ todas sus acciones.

${ }^{j}$ El cuarto participio de la serie comenzada en el v. 5, por consiguiente, lo interpretamos como una acción presente que continúa haciendo Dios. Esta es una de las grandes portadas educativas que el Sal 33 quiere expresar. Este verbo, en hebreo hayyōṣêr, es un participio qal de yāṣar: 
"formar"; este verbo tiene una clara connotación creacional, ya que lo encontramos en Gn 2,7.8.19 en referencia a la creación del hombre a partir del barro.

${ }^{k}$ Luego del cuarto participio tenemos el término yahad, del cual son posibles tres interpretaciones. La primera es sobre la índole de la totalidad: Dios formó todos los corazones existentes. Segundo, la índole de la singularidad: Dios formó cada corazón; esto siguiendo los LXX, que traduce el término hebreo con katà mónas tàs kardías, "cada corazón". Y tercero, la índole solo creacional: solo Dios formó los corazones; haciendo énfasis en la absoluta y omnipotente acción divina al tener presente el sufijo de la palabra libbām: "los corazones de ellos" 28 . Personalmente nos inclinamos por la segunda interpretación, siguiendo la propuesta de traducción que dan los LXX, ya que el énfasis -dado que estamos hablando de una acción hecha por Dios- lo reconocemos en la fuerza del cuarto participio, que también es un participio hímnico ${ }^{29}$. Además, pensar que los LXX simplemente leyeron otra lección diversa a la que leyeron los masoretas ${ }^{30}$ es una mera conjetura y, como tal, solo es hipótesis y no objetividad textual. Lo objetivo textualmente es que tanto los LXX como los masoretas leyeron lo mismo: $y h d$; y como la interpretación de los LXX nos permite reconocer tanto la índole creacional como la de la singularidad, a razón de esto la preferimos.

${ }^{l}$ El quinto participio es hammēbîn, del verbo bîn, "entender, discernir", que en hifil se debe entender como "comprender" y aquí como adjetivo o sustantivo, indicando inteligencia, maestría o pericia ${ }^{31}$. La raíz bîn, de donde viene el verbo "discernir", es la raíz de la preposición bên, que traduce "entre" en hebreo, la cual es el estado constructo de un bayin inexistente cuyo significado es "distinción" o "intervalo" 32 . Esto resulta muy interesante porque el proceso del "discernimiento" comporta dos realidades: separar y decidir" ${ }^{33}$, es decir, "distinguir" en la realidad "entre" lo que es bueno y lo que es malo; esto es fruto del discernimiento, y así este proceso del discernimiento finaliza con la decisión consciente de optar por lo oportuno, por la acción adecuada que debe hacerse para el bien del momento presente.

28 Cf. Aparicio, Comentario filológico, 200.

29 Cf. Gerstenberger, Psalms, 145.

${ }^{30}$ BHS indica que LXX debió de leer yāhid en vez del yahad del TM; pero con las mismas radicales $Y H D$.

31 Cf. Alonso Schökel, Dizionario, 107.

32 Cf. Joüon - Muraoka, Gramática § 103n.

33 Cf. Colmenares, El discernimiento, 90. 
${ }^{16}$ El rey no vence por un ejército numeroso, ni el guerrero se salva por su gran fuerza,

${ }^{17}$ vano ${ }^{11}$ es el caballo para la guerra,

y por su gran fuerza no se escapa;

${ }^{18}$ están los ojos del Señor sobre sus temerosos, sobre los que esperan en su misericordia,

${ }^{19}$ para salvar de la muerte sus almas,

para reanimarlos en tiempos de hambre.

"La palabra šeqer, "falsedad" o "vanidad", resulta interesante, porque la raíz šqr es utilizada como verbo en Gn 21,23 para expresar el actuar contrario a la alianza contraída, expresándonos que una actuación falsa de esta índole es considerada inadecuada al pacto que se ha establecido entre dos partes ${ }^{34}$. Este uso antiguo de la raíz šqr nos revela el ambiente de las intenciones que esta palabra expresa. Aquí, en Sal 33,17, se nos dice claramente del caballo no que es una mentira, sino que es inútil para conseguir la victoria ${ }^{35}$. Es decir, que la fuerza semántica de šeqer, "falsedad", "vanidad", no recae sobre los caballos, sino sobre aquellos poderosos que van a la guerra olvidándose de Dios, y que el salmista ha mencionado ya en el v. 16 (rey, guerrero). Aparece de esta manera la "vanidad" de querer triunfar sin Dios como una falsedad. Pero nos surge la pregunta: ¿es la vanidad un pecado? En el fondo, ¡ sí! Porque interiormente es romper el pacto con Dios y caer en la idolatría de sí mismo. El salmista, en el v. 17, está condenando la sutil idolatría de la "vanidad", que en el fondo rompe el pacto formado por YHWH en el corazón de cada uno (v. 15a), ya que esta "vanidad" consiste en poner la fe en las fuerzas personales y no en la fuerza de Dios.

${ }^{20}$ Nuestras ${ }^{\mathrm{m}}$ almas esperan en el Señor, nuestro auxilio y nuestro escudo es él;

${ }^{21}$ porque en él se alegran nuestros corazones, porque en su santo nombre confiamos;

${ }^{22}$ sea tu misericordia, ${ }^{\text {n }}$ Señor, sobre nosotros, como lo esperamos nosotros de ti.

${ }^{m}$ Como podemos ver, esta sección conclusiva del salmo está marcada por el cambio a la primera persona del plural, cuyo pronombre se repite en los tres versos de esta sección. Esto ofrece al orante una identificación entre el salmista, los justos del v. 1 y los temerosos del v. 18. Es una estra-

\footnotetext{
34 Cf. Seebass - Beyerle - Grünwaldt, "שֶׁק", GLAT, IX, cols. 871-872.

35 Ib., col. 874.
} 
tegia retórica de sutil maestría pedagógica, que busca comunicar una idea testimonial: el salmista, como educador, está dando testimonio de la alegría del corazón que significa confiar plenamente en aquel que ha creado todo, YHWH, el Dios que nos ha escogido como propiedad suya (v. 12).

${ }^{n}$ El término hesed: "misericordia", ya había aparecido en los vv. 5.18.22 y constituye el leitmotiv del Sal 33, ya que el término hace una inclusión entre el inicio (v. 5) y el final del cuerpo del salmo (v. 18), verificación que delimita el corpus del himno y que nos ha ayudado a reconocer nuestra propuesta de estructura. Además aparece como afirmación orante en la conclusión (v. 22). No por casualidad este v. 22 es una invocación grandiosa que ha sido tomada por la liturgia católica para concluir el Te Deum cristiano.

\section{Una propuesta de estructura para el Salmo 33}

Así como ya hemos anticipado en la disposición del análisis morfosintáctico y semántico, reconocemos en el Sal 33 la estructura básica de un himno, a saber: introducción (vv. 1-4), corpus (vv. 5-19) y conclusión (vv. 20-22). Según la investigación que hemos realizado, podemos verificar la existencia de mucha divergencia entre los autores acerca de la estructura del salmo, sobre todo del corpus, como dice Ravasi ${ }^{36}$.

A pesar de esto consideramos que existen pistas textuales que nos hacen ver una libre estructura sapiencial artístico-temática dentro del corpus que va más allá de la métrica tradicional del himno hebreo, como podemos reconocer, por ejemplo, en el Sal $8^{37}$. Además, teniendo presente la exhortación que hace Lohfink de no reducir a una simple fórmula la relación retórica del poema ${ }^{38}$, reconocemos la presencia de dos modelos de lectura en el salmo: uno concéntrico y otro lineal, como sucede en el Sal 29. A pesar de esto nos resulta interesante el énfasis que hace Zenger, evidenciado en el Sal 33 la importancia del término ḥesed, "misericordia" (vv. 5.18.22), reconociendo en este concepto la línea que une transversalmente el corpus del salmo desde el inicio (v. 5) hasta el final (v. 18), y enlazándolo con la conclusión del mismo (v. 22). Zenger, viendo esta evidencia, sugiere una lectura continua y lineal del Sal $33^{39}$.

\footnotetext{
36 Cf. Ravasi, Salmi I, 598.

37 Cf. Barbiero, Il regno, 127.

38 Cf. Lohfink, “Bundesformel”, 100.

39 Cf. Zenger, "Es sei deine Liebe”, 358.
} 
Ahora, partiendo de esta lectura lineal del salmo, proponemos la siguiente estructura del himno, y sobre todo haremos hincapié en el corpus (vv. 5-19), estructurándolo en cinco temáticas que hemos denominado "enseñanzas".

\subsection{Introducción (vv. 1-4)}

Como ya hemos visto, esta está marcada por los cinco imperativos ("exulten de alegría", "den gracias", "entónenle a él", "canten a él” e "interpreten bien") ${ }^{40}$, con los cuales el salmista exhorta a la alabanza a aquellos que son "justos", es decir, a los "justos" del Sal 32, a los "perdonados", a los que han experimentado el dolor de la culpa $(32,4)$ y han confesado sus pecados (32,5b). Estos -los șaddîqîm del Sal 32- han experimentado la alegría de sentirse perdonados por Dios (32,5c). A estos los invita el salmista a exultar de alegría con el Sal 33. Son estos "perdonados" los "justos" que dan gracias y los que pueden cantar el "cántico nuevo" que menciona el v. 3a, y que es todo el Sal 33: una alabanza a Dios creador porque ha hecho todo con misericordia y continúa formando hasta la intimidad del ser humano, discerniendo todas sus acciones (v. 15). También desde el punto de vista textual consideramos el v. 4 como parte de la introducción, a razón de leer el kî inicial -que traducimos "porque"-como la ampliación explicativa de por qué se invita a la alabanza ${ }^{41}$. Este "porque" implica la conciencia de la rectitud de la Palabra de Dios, la cual se manifiesta en la certeza de que "Dios es siempre fiel", a pesar de nuestro pecado ${ }^{42}$.

\subsection{I $I^{a}$ enseñanza: "El acto creacional" (vv. 5-7)}

Esta enseñanza está signada por la presencia del primer participio de la serie de cinco que están referidos a YHWH, y de cuya serie en nuestra primera enseñanza hay tres, a saber: 'ōhēb, "amando" (v. 5), kōnēs, "reuniendo" (v. 7a) y nōtēn, "dando" (v. 7b). El salmista busca transmitir la

40 Cf. Schaefer, Psalms, 81.

41 Cf. GunKEL, Introducción, 57. De la misma manera ve el kî inicial: cf. GeRstenBeRGER, Psalms, 143; cf. LoRenzIN, I Salmi, 152; y también Brueggemann, solo que este último autor ve como parte de la introducción también el v. 5, reconociendo que los vv. 4.5 son un pequeño credo dirigido a YHWH que utiliza el salmista aquí para explicar el porqué de la invitación a alabar al Señor, cf. Brueggeman, Message, 34.

42 Cf. en el v. 4b: 'ěmûnāh, que viene de la raíz 'mn, "ser fiel”, “confiable”. 
enseñanza central de la confesión teológica, la cual es: que Dios es fiel. Esto lo hace a través de las palabras del v. 5b: "La hesed del Señor llena la tierra" ${ }^{43}$. Por otro lado es frecuente reconocer en los himnos el paso de la introducción al corpus del salmo a través del uso de participios añadidos al nombre de Dios (Sal 9,12; 136,3; 144,1); estos verbos aparecen con frecuencia en "series de participios", lo cual es un signo de su importancia constitutiva como parte importante del himno ${ }^{44}$. De estos participios puestos en "serie" es ejemplo nuestro Sal 33, ya que encontramos en él siete participios (vv. 5.6[2x].7.15[2x].16.18), de los cuales cinco están referidos a YHWH (vv. 5.6[2x].7.15[2x]). Es a estos cinco que consideramos una "serie de participios" que expresan acciones de Dios que él continúa realizando en su creación como creatio continua, de la misma manera que como se reconoce Gn 2,4a. Con esta "serie de participios", el autor no solo se refiere a la creación inicial, sino que busca revelar a sus destinatarios el acto continuado y presente del Dios creador, que sigue recreando a través de su mirada, con la cual brinda protección y cuidado a su creación (cf. vv. 1314). Quedan evidenciados de esta manera dos indicios textuales para reconocer el inicio del corpus del salmo en el v. 5; uno sería el primer participio que inicia la "serie", y el segundo sería la presencia del término ḥesed, "misericordia", que inicia el leitmotiv de la lectura lineal del Sal 33.

\subsection{II ${ }^{\mathrm{a}}$ enseñanza: "El temor de Dios" (vv. 8-9)}

Desde el punto de vista textual vemos la presencia de dos yusivos que son utilizados para expresar el matiz exhortativo de la voluntad del salmista, que busca ser "transmitida" a sus destinatarios orantes ${ }^{45}$. Estos yusivos marcan el inicio de una segunda sección temática del corpus que nosotros reconocemos como II ${ }^{a}$ enseñanza. El v. 9 es parte de esta enseñanza, porque representa la ampliación explicativa de la exhortación hecha en el v. 8; esto en razón del kî, "porque", que da inicio al v. 9. La enseñanza que el salmista desea transmitir es la temática sapiencial del "temor de Dios", utilizando como recurso retórico la persuasión que provoca en el orante la mención del poder de la Palabra divina, la cual es eficaz y hace surgir lo

43 Cf. JacoBson, “The hesed”, 318.

44 Cf. GUNKEL, Introducción, 59: "También en este caso el origen de las series de participios hemos de buscarlo en el entusiasmo que el poeta sentía por su Dios: su corazón se siente lleno de su obra, de las gracias que reparte con tanta abundancia".

45 Cf. Joüon - Muraoka, Gramática § $114 h$. 
que pronuncia, porque Dios lo llama a la existencia. Nos resulta interesante evidenciar que esta eficacia de la Palabra es atribuida solo a Dios por parte del salmista, lo que también representa un contenido educativo que se busca "transmitir". En efecto, el deseo de todo rey es que lo que él diga se haga. Y aquí el salmista está expresando que esta eficacia solo la tiene la Palabra de YHWH y no la de ningún rey sobre la tierra, por muy poderoso que sea. No por casualidad se hace referencia al rey y al guerrero en el v. 16. Afirma Kraus que esta conciencia de la eficacia creadora de la Palabra divina ya es una idea antigua presente en civilizaciones como la mesopotámica (Oración con las manos alzadas dirigida a Nanna) y la egipcia (Inscripción de Menfis) ${ }^{46}$. Pero el punto diferencial entre la conciencia hebrea de la Palabra y la conciencia extrabíblica de la eficacia de la palabra divina está en el reconocimiento del señorío de YHWH sobre toda la creación ${ }^{47}$. Esto marca un punto de interrelación teológica entre el v. 9 y el v. 14, que habla del "trono" desde donde Dios mira; y también nos conecta con una temática ya introducida en el Salterio con Sal 2,4. De la misma manera, el reconocimiento de este señorío de YHWH nos da una pista para la interpretación original que da la sabiduría hebrea a esta conciencia teológica de la Palabra creadora, la cual podría haber formado parte del imaginario colectivo de las culturas del antiguo Cercano Oriente. Podríamos estar en presencia de un elemento perteneciente al background cultural común del Cercano Oriente ${ }^{48}$.

\subsection{III ${ }^{a}$ enseñanza: "La estabilidad del “ășat $Y H W H ”(v v . ~ 10-11)$}

Notamos en estos versos un paralelismo que pone en antítesis 'ăṣat gôyim, el "plan de las naciones", y maḩ̌̌ebôt 'ammîm, los "proyectos de los pueblos" (v. 10), por un lado, con 'ășat YHWH, el "plan del Señor”, y maḥ̌sebôt libbô, los "proyectos de su corazón" (v. 11), por el otro. Es decir, estamos hablando de un "paralelismo antitético" que signa estos vv. 10.11 y nos permite leerlos en unidad, reconociendo en ellos la tercera enseñanza que el salmista desea transmitir a sus destinatarios orantes. Esta enseñanza es la permanencia del plan de Dios, el cual es siempre estable (v. 11a). Es ofrecer al orante un horizonte de esperanza, ya que, luego de haber reconocido a YHWH como el creador de todo (cf. I $I^{a}$ enseñanza, vv. 5-7), ahora le

${ }^{46}$ Cf. Kraus, Los Salmos, I, 535.

${ }^{47}$ Cf. Ib., 536.

48 Cf. Giuntoli, Genesi 1-11, 73-80. 
revela el salmista al orante que Dios tiene "proyectos" en su corazón (v. 11b) que son estables; y que ninguna nación, por muy poderosa que parezca, cambiará o dará nuevo rumbo al plan del Señor, que subsiste por siempre.

\subsection{IV enseñanza: "La formación del corazón” (vv. 12-15)}

Está marcada por el macarismo que la inicia ('ašrê, "bienaventurada"). Y, a nuestro parecer, los vv. 13-15 explican esta bienaventuranza de una manera hímnica y no solo argumentativa ${ }^{49}$. Es decir, una nación es bienaventurada porque Dios la cuida con su mirada, ya que él ha formado la intimidad de cada uno de sus miembros ${ }^{50}$. Esta formación es la que nos posibilita llegar a ser el pueblo de su propiedad (v. 12b). Por otra parte, no podemos dejar de reconocer la centralidad de este v. 12 en el conjunto del Sal 33 desde el punto de vista numérico. En efecto, de las 161 palabras que el salmo tiene en el TM ( $\sin$ contar los maqqef), hay 80 palabras antes y 80 palabras después de 'ašrê. Esto nos habla de la centralidad sapiencial del salmo, ya que pone en el centro de su enseñanza la "bienaventuranza", que, como ya hemos visto, inicia todo el Salterio (Sal 1,1). Pero esta evidencia de centralidad hemos de leerla en su integralidad: si separamos el v. 12 de los vv. 13-15, se corre el riesgo de entender la elección como fruto de la propia decisión, convirtiéndose en una pretensión: se diría que este pueblo -entre los muchos pueblos y naciones- ha decidido ser de Dios. Pero esta no es la idea que el salmista quiere expresar en un nivel inicial o fundacional. Más bien, desde una intencionalidad educativa, el salmista busca "transmitir" la enseñanza de que somos propiedad de Dios (v. 12b) porque él nos ha formado (v. 15a) y nos continúa formando, discerniendo nuestras acciones libres, esperando que se encaminen hacia su estable plan universal de salvación y liberación. Esto significa considerar el sentido universal de la propiedad divina; todos podemos ser su propiedad, y no solamente un pueblo. En la lógica del Sal 33, todos estamos llamados a esta bienaventuranza: no es casual que en ningún momento el salmista mencione a Israel en la extensión del salmo.

49 También observan esta división de los vv. 12-15: Gerstengerger, Psalms, 144; LoREnZIN, I Salmim 153; JACOBSON, "The hesed”, 316.

50 Cf. Alonso Schökel - Carniti, Salmos, I, 501. 


\section{6. $V$ a enseñanza: "La mentira de la vanidad" (vv. 16-19)}

Esta sección está marcada por la presentación de un nuevo motivo que se ha anticipado indirectamente en la II ${ }^{a}$ enseñanza con la eficacia de la Palabra de YHWH: el de la ineficacia de las fuerzas humanas para conseguir la salvación ${ }^{51}$. Consideramos que el tema de la "salvación" sirve de inclusión para toda esta sección o enseñanza. La inclusión es signada por el uso del verbo nṣl, "salvar", en los vv. 16b ("ni el guerrero se salva por su gran fuerza") y 19a ("para salvar de la muerte sus almas"). Esta conciencia de unidad en los vv. 16-19 a partir del tema de la "salvación" nos permite reconocer una comparación que hace el salmista. Compara las aptitudes de los poderosos (rey y guerrero, v. 16) con la de los temerosos de Dios (v. 18b). Los poderosos ponen su confianza en el ejército (v. 16a), en la fuerza (vv. 16b.17b), en sus caballerías (v. 17a), mientras que los temerosos de Dios esperan en su misericordia (v. 18b), es decir, ponen su absoluta confianza en Dios: en aquel que es creador de todo, que tiene un plan que subsiste por siempre y que permanece por los siglos (v. 11a) ${ }^{52}$. Esta metáfora militar, de la cual muchos autores han hablado ${ }^{53}$, es calificada por el salmista como "vana" (v. 17), como una aparente omnipotencia que simplemente es "mentira" e ineficaz para la salvación. Nos resulta interesante evidenciar cómo, con este término šeqer, "falsedad" o "vanidad", del v. 17, el salmista hace una antítesis con el término 'ěmûnāh, "fidelidad" "confiabilidad", del v. 4. A la "fidelidad" de Dios, el salmista contrapone antitéticamente la "mentira" de los poderosos, que intentan manipular a las masas prometiendo lo que no tienen y nunca podrán dar: la salvación de la vida. Sigue siendo esta una "mentira" muy actual que algunos de nuestros pueblos latinoamericanos han padecido y otros continúan padeciendo. Evidenciar esta "mentira", la omnipotencia de los poderosos, es el centro de la quinta enseñanza que el salmista, pedagógicamente, está transmitiendo a sus destinatarios orantes con el Sal 33.

\subsection{Conclusión (vv. 20-22)}

Está señalada por el cambio a la primera persona del plural, lo cual constituye una estrategia retórica testimonial. En efecto, la secuencia litúr-

51 Cf. JacoBson, “The hesed”, 317.

52 Cf. Ravasi, Salmi I, 606. Este contraste también lo ve Mays, Psalms, 151.

53 Cf. Briggs, Psalms, I, 290; Brueggeman, Message, 35; Alonso Schökel - Carniti, Salmos, I, 501; JAcoBson, "The hesed”, 317. 
gica que pasa del "ustedes" (vv. 1-4) al "nosotros" (vv. 20-22) ${ }^{54}$ revela la intención de mostrarse el salmista como parte de aquella congregación de "justos-perdonados" que ahora se alegran en el Señor (v. 21a). El salmista ha invitado a "exultar de alegría" (v. 1a) gracias a que él ha experimentado la alegría del perdón. Por eso ahora es testigo fiel y heraldo confiable de ese misterio de amor que es la misericordia del Señor. Por eso está sobre nosotros su misericordia, porque es en Dios en quien esperamos, y no en los poderosos, sean estos reyes victoriosos o guerreros fuertes.

\section{La IV enseñanza: "La formación del corazón” (vv. 12-15)}

Consideramos esta cuarta enseñanza como central en el conjunto del Sal 33, y esto por varias razones que más o menos hemos anticipado. En primer lugar, porque inicia con 'ašrê, "bienaventurada", el centro numérico del salmo: ochenta palabras antes y ochenta después.

Segundo, porque esta palabra nos ofrece una típica introducción sapiencial que inicia una línea de enseñanza ${ }^{55}$, un contenido educativo que considera el salmista imprescindible para la formación del orante. Como ya indicamos, 'ašrê inicia el Salterio (Sal 1,1). También encontramos esta palabra en Sir 14,20 (ms A), dando inicio al texto sobre los beneficios de la hokmāh, "sabiduría". Allí, la bienaventuranza no está solo en evitar, como en Sal 1, sino que su focus está en el hacer: la bienaventuranza de la sabiduría consiste en hacer lo que es agradable al Señor, y no solamente evitar lo malo ${ }^{56}$. Consideramos que es en este horizonte sapiencial posexílico tardío de Ben Sira donde se mueve la redacción y composición del Sal 33 ${ }^{57}$.

Tercero, es presentada en esta cuarta enseñanza la formación del corazón (v. 15a), es decir, de la interioridad del ser humano, de todo ser humano, de cada ser humano. Pero no como una creación ya realizada, sino

54 Cf. Gerstenberger, Psalms, 145.

55 Cf. ib.

56 Cf. Jones, “Psalm 1", 540.

57 Nos dice al respecto Gunkel que “la misma asimilación de ciertos elementos de la literatura sapiencial, tan popular en aquella época, constituye un signo del proceso de descomposición del género hímnico que, poco a poco, va perdiendo la frescura y el entusiasmo de los himnos primitivos. Por consiguiente, apoyados en criterios de dependencia literaria con otros textos, y a partir de las similitudes en el vocabulario, podríamos datar en esta última época del género literario laprox. 300 a. C.I a los Salmos 33; 68; 96; 98; 100; 105; 111; 113; 145; 147; 148; 150", cf. GUNKEL, Introducción, 107. 
como una formación que está en pleno desarrollo (v. 15a). Dios creó la intimidad del ser humano otorgándole el don de la libertad, pero aún continúa formándola, discerniendo todas sus acciones libres o esclavas (v. 15b).

Si en los vv. 6-9 se habla de la Palabra creadora de Dios, en los vv. 13-14 se habla de su mirada que acompaña. Este hecho del observar de Dios evidencia el cuidado divino por la creación que él ha hecho; Dios cuida a su creatura con su mirada. Vemos en los vv. 13-14 los tres verbos del ver, los cuales forman parte de la "péntada" de los términos referidos a la vista (vv. 13.14.15.18) ${ }^{58}$. Estos tres verbos, en los cuales se reconoce una gradación y que sirven de preámbulo para presentar el discernimiento, son:

- hibbît: es un hifil qatal de la raíz nbț, y significa "mirar", "poner atención", "fijar la mirada". Lo encontramos, por ejemplo, en 1 Sam 24,9 y $\operatorname{Pr} 4,25$;

- rā'āh: es un qal qatal de la raíz r'h, y significa “ver". Lo encontramos en textos como Ex 3,23; Dt 1,19; Pr 23,33;

- hišgîah: es un hifil qatal de la raíz šgḥ, y significa "observar". Podemos encontrarlo fuera de aquí solo en Is 14,16 y en $\mathrm{Ct}$ 2,9, donde se refiere a un hacer presente a aquel que está mirando; como si la mirada del que nos ve nos delatara.

Estos verbos no solo hablan de una mirada lejana, sino que verifican una gradación hacia la cercanía de una presencia. Comienzan con un "mirar" (hibbît que es atento; luego se pasa a un "ver" ( $r \bar{a}$ 'āh) que es tangible y experiencial; y se llega a un "observar" (hišgîah) que hace referencia en hebreo a la presencia del que mira. El poeta sagrado, con esta gradación de significados, busca expresar la realidad de que Dios está mirando al ser humano $^{59}$. Es decir, lo está acompañando en todo momento la presencia del que lo ha creado.

\subsection{La acción formativa de Dios}

Luego de evidenciar esta gradación de significados en el concepto del "ver" debemos reconocer la fuerza semántica del "ver de Dios" con relación al "crear". El "ver de Dios" es un acto sucesivo a la creación, lo que expresa el cuidado y la custodia con la cual Dios acompaña a la creatura que creó. El "ver de Dios" se entiende como los cuidados con los cuales

58 Cf. Schaefer, Psalms, 82.

59 Como se sabe, en hebreo la forma verbal qatal expresa tanto el presente como el pasado simple. 
Dios está cercano a su creatura, la cual camina en medio de la historia, a veces cerca de Dios y en otras oportunidades lejos de su presencia, esto solo por decisión propia.

De esta manera llegamos a nuestro v. 15, que, como ya hemos dicho, comienza con un verbo en participio: hayyōṣēr, part. qal de yāṣar, que significa "formar", "plasmar", "modelar". Es un típico verbo de creación que encontramos, por ejemplo, en Gn 2,7-8 ${ }^{60}$. Dentro del Sal 33, este participio forma parte de la serie de participios que hacen referencia a Dios (cf. vv. 5.7). La serie expresa la continuidad de la obra del Creador, la creatio continua. Por consiguiente, ¿quién realiza la acción de formar la interioridad del ser humano? Dios.

Este verbo "formar" tiene como objeto el lēb, el "corazón”. En el AT, más que un mero órgano corporal en sí es el sitio de la actividad mental y de la actitud moral, ética y espiritual. En cierto sentido, el corazón es el motor del carácter de una persona; de hecho, muchas veces la palabra lēb se traduce por "mente". El término lēb y su sinónimo lēbāb aparecen unas 850 veces en el AT. El libro de los Proverbios afirma que el corazón es la fuente de pensamientos, palabras, acciones y sentimientos, sean estos buenos o malos $(\operatorname{Pr} 4,23)^{61}$. Por otro lado, como ya hemos visto, el adverbio yaḥad es traducido por los LXX como katà mónas tàs kardías, "cada corazón", "individualmente" ${ }^{62}$; lo que nos ayuda a reconocer el carácter creacional de cada individuo, como una preocupación de la cual Dios mismo se ha hecho cargo.

Alonso Schökel dice que el Sal 33 distingue o casi opone la creación del cielo y los astros -a los cuales hace existir Dios solo con su Palabra escueta- a la del corazón humano, esa intimidad que piensa y decide; pues a esta la ha hecho existir mediante una tarea artesanal. Dios ha modelado cada una (yahad) de las intimidades humanas hasta en lo más diferencial ${ }^{63}$.

Pero hayyōseer r, al encontrarse en participio, no solo evidencia este carácter creacional que pone a Dios como causa primera de la existencia de la intimidad del ser humano, sino que también expresa que es una realidad que continúa formándose. De ahí el hecho de evidenciar la creatio conti-

60 Podemos ayudarnos para reconocer la fuerza semántica de este verbo consultando pasajes como Is 29,16; 45,9-12; Jr 18,2-10; Sal 94,9-11; Sal 139,6-12. De esta manera podemos ver el peso de este verbo yāṣar, "formar", en el AT.

61 Cf. Carpenter - Comfort, Glosario, 54, sub voce "corazón".

${ }^{62}$ La Vulgata $(\mathrm{Vg})$, en el llamado Psalterium Gallicanum, lo traduce: singillatim, "singularmente, uno por uno".

${ }^{63}$ Cf. Alonso Schökel - Carniti, Salmos, I, 500. 
nua de los vv. 5.7, que a su vez releen Gn 2,3. Es decir, el acto formativo del corazón del ser humano y de su individualidad es una formación que continúa realizando Dios a través de su mirada (vv. 13-14), que nunca se aparta del corazón del hombre ni de su intimidad.

\subsection{La participación en esta obra formativa divina}

En esta obra formativa que es de Dios está llamado a "participar" el educador cristiano a través de un "proyecto educativo eclesial" ${ }^{64}$ que tenga como fundamento la educación al "temor de Dios" (v. 18; Pr 1,7). Esta orientación de la educación al temor de Dios es propiamente la identidad de la educación cristiana (cf. Ef 6,1-4), que encuentra en el discernimiento el matiz ideal que forma hombres y mujeres libres, capaces de reconocer a Dios como el Señor de sus vidas.

A partir de constatar que Dios forma discerniendo las acciones humanas (v. 15), la formación en el discernimiento es la clave escriturística que queremos individuar en la lectura exegética de Sal 33,15. Dios forma el corazón del ser humano discerniendo sus acciones. Esto se reconoce a partir de la presencia de los participios hímnicos del v. 15 hayyōṣerr, "formando", y hammēbîn, "discerniendo", que hemos leído como una obra presente que Dios continúa realizando. Se trata de la custodia que él hace de su creatura a través de su mirada actual y presente en el caminar histórico del ser humano. De la misma manera se espera del educador cristiano que contribuya a la formación de la personalidad del educando cristiano discerniendo sus acciones y no simplemente condenándolas sin un debido proceso de discernimiento.

El camino del discernimiento es el camino que Dios ha tomado para la formación continua del corazón, para su creatio continua, que renueva la vida de su gran obra excepcional, el hombre y la mujer. Dios "forma discerniendo" (v. 15). De la misma manera, el educador cristiano encuentra aquí un principio escriturístico que da identidad e iluminación a su rol pedagógico. El educador cristiano participa de la obra formativa de Dios discerniendo las acciones del educando cristiano y reconociendo el lugar donde solo Dios entra: la intimidad del ser humano. Preparar la conciencia del

${ }^{64}$ Es una denominación proyectual que, a la luz de la TdE se buscará formular y de la cual se intentará reconocer la viabilidad práctica. Por ahora es una hipótesis que llevamos adelante y que requerirá una futura publicación del material formulado a la luz del diálogo recíproco-asimétrico entre Sagradas Escrituras y ciencias de la educación. 
educando para reconocer a Dios en su intimidad es la forma de "participar" el educador cristiano en la obra formativa divina del corazón del ser humano; y el fundamento de esta preparación es la formación para el temor del Señor (Pr 1,7).

El educador cristiano debe entender también que Dios continúa formando la interioridad del educando (cf. el participio del v. 15a). Es esta la certeza de fe que el educador creyente debe vivir en el ejercicio de su rol como maestro. Por consiguiente, en su discernimiento debe reconocer cuál es el espacio en la vida del educando, donde solo Dios entra; y reconocer que, en la intimidad entre Dios y el educando, es donde se vive la experiencia de discernir la vida y de decidir lo agradable, lo oportuno, lo perfecto (Rom 12,2).

De tal manera la "formación en el discernimiento" lleva inevitablemente la intención de formar la conciencia del educando hacia una experiencia libre de la intimidad divina donde el educando sea consciente de que Dios lo ve y lo escucha; no solamente para juzgarlo, sino para cuidarlo, para fortalecerlo, para instruirlo con la "sabiduría del corazón", aquella que solo Dios otorga (cf. 1 Re 3,9).

\section{Conclusión: el fruto de la estructura propuesta}

Así como hemos evidenciado, hablamos de cinco enseñanzas presentes en el corpus del Sal 33, a saber:

$I^{a}$ enseñanza: el acto creacional (vv. 5-7);

II ${ }^{\mathrm{a}}$ enseñanza: el temor de Dios (vv. 8-9);

III ${ }^{a}$ enseñanza: la estabilidad del 'ăṣat YHWH (vv. 10-11);

$I^{a}$ enseñanza: la formación del corazón (vv. 12-15);

$\mathrm{V}^{\mathrm{a}}$ enseñanza: la mentira de la vanidad (vv. 16-19).

Si bien las "estrofas" del salmo obedecen a una métrica más o menos exacta ${ }^{65}$, el reconocimiento de cada motivo temático del salmista en este Sal 33 no sigue una exactitud métrico-poética. Como hemos evidenciado, estos "motivos" temáticos, que hemos llamado "enseñanzas", están marcados textual y sintácticamente en el salmo: la primera enseñanza (vv. 5-7) está signada por el uso de los participios que expresan acciones de $\mathrm{YHWH}$ (vv. 5a.7); la segunda (vv. 8-9) está marcada por el uso de los yusivos (v. 8); la tercera (vv. 10-11) está construida en paralelismo antitético; la cuarta (vv. 12-15) está signada al inicio por el macarismo y al final por el hecho

${ }^{65}$ Cf. Gerstenberger, Psalms, 144. 
de comenzar en el v. 16 un argumento nuevo; la quinta (vv. 16-19) está establecida por una comparación de aptitudes entre los poderosos (rey, guerrero) y los temerosos de Dios, los que esperan en su misericordia.

Debemos reconocer también que si la métrica, en la poesía, obedece más a los momentos clásicos de la composición -tal como sucede en la música, en el arte, en la escultura-, la ausencia de métrica obedece más bien a los momentos libres y maduros de la composición, como cuando el concepto o estilo ya ha sido degustado y existe la necesidad de actualizarlo y hacerlo más atrayente. Estos tiempos maduros de la composición artística siempre son los más recientes. Y no por casualidad nuestro Sal 33 ha sido siempre reconocido como una composición tardía; tal vez obedeciendo a momentos maduros de la composición sapiencial sálmica del pueblo hebreo ${ }^{66}$.

Estas cinco enseñanzas que estructuran el corpus del Sal 33 podrían ser leídas en relación con la péntada estructural que marca el Salterio, distribuido en cinco libros ${ }^{67}$, y con el llamado Pentateuco sapiencial (Proverbios, Job, Qohélet, Sirácida y Sabiduría $)^{68}$, por lo cual se estaría haciendo referencia también a los cinco libros de la Torá. Aparece de esta manera el Sal 33, estructurado en cinco enseñanzas, como una relectura hímnica de temas sapienciales, planteados pedagógicamente en péntada al estilo de la Torá de Israel, que en cinco libros intenta dar testimonio de la cercanía y del acompañamiento del Dios creador para con su pueblo escogido, al cual cuida, protege y forma con su mirada (vv. 13-14), discerniendo sus acciones (v. 15).

A través de esta exposición en péntada de enseñanzas sapienciales, el salmista revela su estrategia pedagógica y su intención educativa en este salmo alfabetizante, conformado por veintidós versos, el número de las letras del alfabeto hebreo.

Poéticamente hablando, podemos ver el Sal 33 como la melodía de la alabanza a YHWH que pasa por el "pentagrama de la enseñanza", brindando al orante perdonado por Dios la posibilidad de cantar un cántico nuevo al Señor. Queda así evidenciado el horizonte educativo (cinco ense-

66 Si bien no compartimos la calificación poco entusiasta que hace Gunkel del Salmo 33 como "ejercicio escolar mediocre" (GUNkEL, Introducción, 139), sí estamos de acuerdo con Barbiero en que tampoco hay que sobrevalorarlo como obra poética. Sin embargo, el análisis estructural y la profundidad sapiencial de las cinco "enseñanzas" del salmo que hemos puesto en evidencia revelan una obra literaria de alto nivel artístico.

${ }^{67}$ Cf. Brown, Psalms, 109-110.

${ }^{68}$ Cf. Mazzinghi, Il Pentateuco sapienziale, 9. 
ñanzas) y pedagógico (estilo hímnico) del salmo, al reconocer el contenido educativo que el salmista desea transmitir a sus destinatarios orantes.

Estamos hablando de que el Sal 33 es una estrategia pedagógica de transmisión educativa que desea transmitir argumentos sapienciales centrales para la vida de Israel. Evidenciar esta estrategia pedagógica es el fruto de la estructura propuesta para el corpus del Sal 33. El salmista está convencido de que, si estas importantes enseñanzas no se aprenden, la identidad de Israel podría estar en peligro.

Asume de esta manera la enseñanza sapiencial una importancia trascendental en la vida del pueblo escogido. Esta trascendentalidad educativa de la enseñanza sapiencial supone, para la TdE, una implicación fundamental: encamina a la educación cristiana a poner los ojos en la Escritura y a dejarse inspirar por ella, con miras a descubrir principios escriturísticos que ayuden en la formulación de criteriologías fructuosas que contribuyan al diálogo recíproco-asimétrico entre el dato humano (ciencias de la educación) y el dato de fe (Sagradas Escrituras). Todo esto con miras a construir proyectos educativos que verdaderamente se alimenten de la sabiduría sapiencial revelada en la Escritura.

\section{Bibliografía}

Alonso Schökel, L., Dizionario di ebraico biblico, Milano 2013.

-, Manual de poética hebrea, Madrid 1988.

-, Salmos. I, Estella 1992.

Alter, R., The Book of Psalms, New York 2007.

Aparicio, A., Comentario filológico a los Salmos y al Cantar de los Cantares, Madrid 2012.

Ammassari, A., Il Salterio latino di Pietro. I, Roma 1987.

BArbiero, G., Il regno di Jhwh e del suo Messia. Salmi scelti dal primo libro del Salterio, Roma 2008.

-, Dai Salmi al Salterio, Trapani 2014.

Botterweck, G. J. - Ringgren, H. - Fabry, H.-J. (eds.), Grande lessico dell'Antico Testamento, Brescia 2005.

Brueggeman, W., The Message of the Psalms, Minneapolis 1984.

Briggs, Ch. A. - Briggs, E. G., The Book of Psalms. I (The International Critical Commentary), Edinburgh 1976.

Brown, W. P., Psalms, Nashville 2010.

Carpenter, E. E. - Comfort, Ph. W., Glosario Holman de términos bíblicos, Nashville 2000. 
Colmenares, R., El discernimiento eclesial en el Concilio Vaticano II como categoría teológica que funda la acción de la Iglesia, Maracaibo 2017.

ChILDS, B. S., Introduction to the Old Testament as Scripture, London 1979.

Dahood, M., Psalms 1: 1-50 (Anchor Bible Commentary), New York 1966.

Firth, D., "The Teaching of the Psalms", en Ph. Johnston - D. Firth (eds.), Interpreting the Psalms, Downers Grove 2005, 159-174.

Gerstenberger, E., Psalms, Part 1, with an Introduction to Cultic Poetry (FOTL 14), Grand Rapids 1988.

Giuntoli, F., Genesi 1-11, Milano 2013.

Groppo, G., "Teologia dell'Educazione”, en M. LAENG (eds.), Enciclopedia Pedagogica. VI, Brescia 1999, 958-982.

Hossfeld, F. L. - Zenger, E., Die Psalmen. I: Psalm 1-50 (NEB.AT 29), Würzburg 1993.

JaCOBSON, R. A., "Psalm 33: The hesed of the Lord Fills the Earth", en N. Declaisse-WALFORD - R. A. JACOBSON (eds.), The Book of Psalms (NICOT), Grand Rapids 2014, 310-320.

Jones, S. C., "Psalm 1 and the Hermeneutics of Torah", Bib 97 (2016) 537551.

Joüon, P. - Muraoka, T., Gramática del hebreo bíblico, Estella 2007.

Kraus, H. J., Los Salmos. I, Salamanca 1993.

Limburg, J., Psalms, Louisville 2000.

Lohfink, N., "Die Bundesformel in Psalm 33", en N. LOHFink - E. ZeNGER (eds.), Der Gott Israels und die Völker: Untersuchungen zum Jesajabuch und zu den Psalmen (SBS 154), Stuttgart 1994, 84-116.

LoREnzIN, T., I Salmi. Nuova versione, introduzione e commento (I libri biblici. Primo Testamento 14), Milano 2001.

Mays, J. L., Psalms, Louisville 1994.

Mazzinghi, L., Il Pentateuco sapienziale, Bologna 2012.

Ravasi, G., Il Libro dei Salmi. Commento e attualizzazione. I, Bologna 2005.

RuIz, E., "Rostros de Dios justo y misericordioso en el Salterio", Estudios Bíblicos 75 (2017) 77-102.

SABetTA, A. "Educare a pensare e a credere nel tempo della crisi della ragione e della sfida educativa", Passione educativa, Roma 2012, 5-26.

Schaefer, K., Psalms, Collegeville 2001.

Vangemeren, W. A., "Psalms", en T. Longman - D. Garland (eds.), The Expositor's Bible Commentary V, Grand Rapids 2008. 
Wilson, G. H., The Editing of Hebrew Psalter, Chicago 1985.

ZENGER, E., "'Es sei deine Liebe, JHWH, über uns!' Beobachtungen zu Aufbau und Theologie von Psalm 33", en R. ACHENBACH - M. ARneth (eds.), "Gerechtigkeit und Recht zu üben" (Gen 18,19). Studien zur altorientalischen und biblischen Rechtsgeschichte, zur Religionsgeschichte Israels und zur Religionssoziologie. FS E. Otto (BZAR 13), Wiesbaden 2009, 350-361.

(recibido: 26/04/17 - aceptado: 20/06/17) 